\title{
TÉCNICA, CIENCIA Y FOMENTO EN ALMADÉN Y SUS REALES MINAS DE AZOGUE EN EL SIGLO XVIII: ANTONIO DEL VILLAR, MAESTRO MAYOR DE OBRAS (1734-1806)
}

\author{
RAFAEL Gil BAUTISTA \\ I.E.S. «Mare Nostrum» (Torrevieja)
}

Fecha de recepción: octubre de 2010

Fecha de aceptación: diciembre de 2010

Desde los más remotos tiempos históricos la riqueza mineral de la Península Ibérica gozó de un considerable renombre en todo el occidente europeo. Entre los grandes yacimientos metalíferos el de Almadén ha de considerarse uno de los más importantes; al menos desde la época romana y musulmana, los restos arqueológicos y las reseñas literarias así lo atestiguan. No obstante será a partir del siglo XVI cuando la utilización del mercurio para el procedimiento de amalgama de oro y plata se convierta en factor estratégico en la consolidación del entonces todopoderoso imperio hispánico.

Tras el arrendamiento a los Fugger (Fúcares), familia de banqueros y prestamistas de Augsburgo que disfrutaron de su arrendamiento desde 1525 hasta 1645, la Corona recobró la explotación de estos ingentes recursos. Será a partir de la segunda mitad del Setecientos cuando estas vetas de cinabrio alcancen su punto más álgido. Buscando la mayor optimización de tan significativo recurso la Corte hizo que desfilasen en ese período hombres de la talla del prestigio naturalista irlandés Guillermo Bowles, del ingeniero y arquitecto Francisco Nangle, de los marinos y científicos Jorge Juan y Antonio de Ulloa o del ilustrado canario Agustín de Betancourt, a quien le dedicaremos unas breves líneas. Pero al mismo tiempo, otros prohombres de ámbito más local, como el médico José Parés y Franqués o el maestro de obras que ahora va a ser objeto de análisis, Antonio del Villar, aportarán cada uno desde sus competencias, los esfuerzos y conocimientos necesarios para engrandecer esta villa mercurial y al mismo tiempo contribuir de forma considerable al sostén económico de la España dieciochesca.

Mientras tanto, la villa minera (nunca mejor adjetivada, pues su nombre actual procede del árabe al-ma'din, la mina) ubicada en el rincón suroeste del Campo de Calatrava, ya próximo a las tierras extremeñas y cordobesas, sobrepuesta durante 
siglos al entramado de galerías mercuriales, ha ido dibujando su trazado urbano en función siempre de las necesidades de los recursos del azogue, ya que de otro modo no se entendería que hubieran visto la luz edificaciones tan señeras como las viviendas que delimitan la plaza de toros hexagonal, el recinto del Hospital de Mineros, la nueva Real Cárcel de Esclavos y Forzados o la construcción de la primera institución académica sobre minería de España.

Abordamos a continuación el estudio de una figura fundamental para el desarrollo urbanístico y para el fomento socioeconómico de Almadén en el momento de su mayor esplendor, la segunda mitad del siglo XVIII. Nos referimos al toledano de cuna y acogido almadenense Antonio del Villar García (Mocejón 1734-Almadén, 1806). Aunque en determinados momentos puede resultar difícil desligar la vida familiar de la profesional, por motivos metodológicos, a la hora de trazar una visión de conjunto de su trayectoria vital en estas tierras calatravas conoceremos primero los rasgos personales más significativos para adentrarnos después en sus ocupaciones y responsabilidades en el consistorio y en el establecimiento minero.

\section{RASGOS BIOGRÁFICOS Y FAMILIARES}

Tras la visita a su villa natal, Mocejón (Toledo), sabemos por su partida de bautismo $^{1}$ que fue sacramentado el 22 de enero de 1734, aunque había nacido el 17 de enero, lo que tal vez justifique el nombre que sus padres eligieron, Antonio de Jesús. Era uno de los muchos vástagos que tuvieron Blas del Villar y Feliciana García, en concreto el undécimo de los doce que hemos hallado. Esta información ratifica la primera noticia que sobre él teníamos, la de su boda en Almadén en septiembre de $1762^{2}$. Gracias a esa partida de desposorio confirmamos que sus orígenes procedían de la comarca toledana de La Sagra, que sus padres fueron también de cuna mocejonera, y que su mujer Francisca Antonia Ramona Aragonés era nativa de Chillón, aunque su suegro era de la manchega Herencia y su suegra chillonera. La ceremonia nupcial fue oficiada por el cura rector de la parroquia de Nuestra Señora de la Estrella, don frey Pedro Gijón Triviño del hábito calatravo.

Respecto a su suegro, tras consultar los datos del Catastro de Ensenada ${ }^{3}$ para la villa minera, sabemos por el memorial que él mismo redacta que se trataba de un hombre de cuarenta años, casado (aunque no cite el nombre de su esposa, Ángela Hidalgo, sí dice que tenía entonces treinta años) y con una única hija menor de dieciocho años, sin especificar su edad. También contaba la familia con la ayuda para la casa de una criada, Cayetana María Ruiz, de veintitrés años. Pero, además de estas breves notas biográficas, merece destacarse su oficio, el de tendero de por menor de mercería

1. Archivo Parroquial de Mocejón (en adelante APMO). Libro de Bautismos no 10, f. 115v.

2. Archivo Diocesano de Ciudad Real (en adelante ADCR). Libro de Desposorios $n^{\circ} 5$ de Nuestra Señora de la Estrella (1738-1767).

3. Archivo Histórico Provincial de Ciudad Real (en adelante AHPCR). Catastro de Ensenada. Legajos 642 y 643 . 
y abacería. Esto le permite tener una posición económica desahogada, ya que en la misma documentación aparece como uno de los asentistas que en 1748 y 1749 habían arrendado las rentas de alcabalas, cientos y millones de esta villa; o unos años después como uno de los suministradores de carne para Almadén, incluso como avalista del escribano municipal Uribe. Al tener como única heredera a Francisca, en el futuro todas sus propiedades pasarán a su mujer e hija, lo que en parte acrecentará la fortuna del matrimonio Villar - Aragonés.

Precisamente de esta pareja, como era bastante habitual en la época, nació una amplia descendencia, once vástagos, posiblemente imitando la numerosa familia que él había tenido. Pero, del mismo modo que eran numerosos los nacimientos, también lo fueron las defunciones; de hecho en el momento de su óbito tan sólo le sobrevivían a Antonio del Villar dos hijos, Juan Manuel y Francisco.

Respecto a la familia de su mujer, sirve de muestra del aluvión poblacional que hacia la villa minera se experimentaba en esos años. Su suegro ya mencionamos que era oriundo de Herencia ${ }^{4}$, en la parroquia de la Concepción de Nuestra Señora fue bautizado en febrero de 1711, figurando como hijo legítimo de Pedro Aragonés y de Ana Manrique, ambos naturales de la villa vecina de Arenas, en el mismo priorato de San Juan. Su suegra, de la vecina Chillón, donde nació en idéntico mes de febrero, pero una década después, en $1721^{5}$. Si a ello le añadimos que sus orígenes eran toledanos muestran el enorme éxodo poblacional que se produjo a lo largo del segundo tramo del siglo XVIII hacia Almadén.

En cuanto al matrimonio en sí, Francisca tuvo descendencia, al menos, entre 1763 y 1788. Con un intervalo aproximado de dos años se producía un nacimiento, lo que nos indica que aprovechó con generosidad su periodo fértil. Como buena chillonera cuando llegó el momento de su óbito, lo que se produciría en el otoño de $1797^{6}$, pidió ser enterrada en el convento de san Antonio que los padres franciscanos tenían extramuros de Chillón y muy cercano al término almadenense. Contaba con 52 años, pero ya había redactado en 1769 testamento $^{7}$, pues una grave enfermedad la tuvo al borde de la muerte.

En lo tocante a nuestro maestro de obras, podemos decir que fue longevo para su época, pues en el momento de su defunción, septiembre de 1806, tenía 62 años. En cualquier caso, sus primeros años en Almadén no fueron precisamente agradables. Entre la documentación notarial manejada nos hemos llevado la sorpresa de encontrar

4. Archivo Parroquial de Herencia (APH). Libro no 10 de Bautismos (1709-1716), f. 51v.

5. ADCR. Libro de Bautismos n 7 de san Juan Bautista y santo Domingo de Silos de Chillón (1701-1721), f. 294v. Según consta en su partida fue bautizada el día 26 de febrero, aunque había nacido el 20.

6. ADCR. Libro de Defunciones $n^{\circ} 6$ de Almadén (1785-1801), f. 285. Allí se registra la siguiente partida fúnebre: Francisca Aragonés, muger que fue de Antonio del Villar. En el convento del sr. San Antonio de Chillón en treze de octubre de mil setecientos noventa y siete se enterro a Francisca Aragones, muger que fue de Antonio del Villar, haviendo recibido la Santa Uncion.

7. AHPCR. Protocolos Notariales. Legajo 04785. El documento se firmó el 22 de noviembre de 1769. 
una fianza que su compañero y colega alarife, Juan Martín Santiso, tuvo que aportar, ya que

contra Antonio del Billar mi conbezino se esta siguiendo en el juzgado de esta villa ... cierta causa criminal sobre suponérsele a tratado ylizitamente con Maria Romera, de la misma bezindad, y que de este trato ylizito a resultado estar embarazada la referida, por cuya causa se paso a poner preso ael referido, como lo esta en la carzel publica de esta villa ${ }^{8}$.

Desconocemos como terminó el affaire. Ignoramos si fue un desliz puntual o se resolvió con prontitud, pero desde luego tuvo que influir en la determinación de desposarse con inmediatez con Francisca Aragonés. Pero si esta fue una de sus vivencias más sonadas y señaladas en el principio de su estancia en Almadén, dos circunstancias destacables van a marcar los años finales de su vida. Como son lo suficientemente significativos nos vamos a detener brevemente en su análisis y comentario. Se trata del permiso matrimonial que deniega en 1795 a su hijo Juan Manuel ${ }^{9}$ y del testamento que redacta en los últimos días de agosto de 1806, cuando intuye cercana su muerte. Veámoslos por separado.

En cuanto a la negativa para autorizar la licencia paterna, la normativa aludida en la disputa entre don Antonio Villar y su hijo Juan Manuel, será la pragmática sanción sobre matrimonios, dictada en marzo de $1776^{10}$. En ella se establecía que los hijos de familia, varones y mujeres menores de veinticinco años, para contraer matrimonio debían pedir y obtener consejo y consentimiento de su padre; en su defecto, de la madre; y si faltaban los dos, de los parientes más próximos.

Si se ha hecho este preámbulo es porque todo lo anterior sucedió, pero con particularidades muy relevantes. Además de todo el embrollo jurídico, pues ambas partes nombraron procuradores y otorgaron poderes para ser usados por personas de su confianza, la exposición de los hechos que realiza Juan Manuel contra su padre resulta significativa por cuanto muestra el fuerte carácter que este debió de tener. Tal vez sea mejor que se explique el joven por sí mismo:

Que por quanto teniendo tratados esponsales con Josefa de los Santos, natural y vecina de la misma villa (de Almadén), noticioso de ello mi padre legitimo D. Antonio del Villar,

8. AHPCR. Protocolos Notariales. Legajo 04782. Resaltamos la fecha en que está redactado, el día 2 de febrero de 1762, sólo unos meses antes de su enlace matrimonial con Francisca, que se legitimó en septiembre de ese año.

9. AHN. Consejos. Superintendencia General de Azogues. Legajo 20190, Expediente 4. «Autos de Antonio del Villar con Manuel del Villar por negación de licencia para contraer matrimonio». No son más que catorce folios, pero tremendamente reveladores.

10. La legislación hispana es abundante sobre la regulación de los contratos matrimoniales, tanto en la etapa medieval como moderna. La Real Pragmática a que se hace mención es la firmada en El Pardo el 23 de marzo de 1776 por Carlos III. En ella quedaba constancia de que había llegado a ser frecuente el abuso cometido por los hijos de contraer matrimonios desiguales sin esperar el consejo y consentimiento paterno, razón por la cual decidió poner remedio a esta situación sancionándola con esta norma. Si se desea ampliar noticia sobre el asunto se puede ver la obra de PÉREZ MolinA, I. y otros: Las mujeres en el antiguo régimen: imagen y realidad: (s. XVI-XVIII). Icaria Editorial, Barcelona, 1994, pp.32-33. 
trató de impedirlo y para ello de su orden y con otras recomendaciones me sacaron de la citada villa llevándome a la ciudad de Cordoba, en donde me presentaron a disposición de aquel sr. Intendente, quien mandó a un sargento de granaderos de estado, me recibiese filiación de soldado, como lo hizo con violencia y en presencia de Manuel García Ximenez, escribano de la villa de Almaden, que me había llevado como en forma de presidiario, en cuyo acto de filiación fueron muchas las amenazas que me hicieron y también la de que me darian de golpes y pondrían en un calabozo, donde no vería la luz en muchos días. Pude escaparme y me presente inmediatamente ante el sr. Corregidor de la explicada ciudad de Cordoba quien enterado del insulto y violencia que se me hacia, me favoreció y dejó en libertad, de la qual usando sin que tropa alguna me buscase me retire a esta de Ciudad Real.

Por no ser más prolijos en los detalles, con las aportaciones que luego se redactan, además de expresar el disgusto por el desaire paterno, no se termina de aclarar cuál fue el final de este litigio, pues las dos partes se dirigen a la Superintendencia de Azogues, ya en agosto, pidiendo que se les comunique (a través de sus procuradores y apoderados) la decisión final. Lo que sí sabemos es que una década después, cuando se produzca el óbito del toledano, Juan Manuel figura como heredero. Por cierto, que tan sólo unos días después, al parecer enfermo, también decidió él mismo testar. Su contrayente ya no es la citada Josefa de los Santos, sino doña Ignacia Cotinel. Ello nos induce a pensar que murió/desapareció la prometida o que se impuso el juicio paterno, pues si se desobedecía éste criterio, además de la sanción correspondiente, se le impedía a él y a sus descendientes heredar o reclamar dotes o legítimas partes de lo legado.

El segundo asunto del que antes hablábamos era el fallecimiento y sobre todo el testamento del maestro de obras, cuando ya viudo, en septiembre de 1806, fue enterrado en el camposanto del Real Hospital de mineros ${ }^{11}$. Muy cercano a las tradiciones almadenenses, como otras tantas familias que se lo podían permitir, mandó que se le amortajase con el hábito de san Francisco y se le rezasen, además de las misas que venían siendo habituales, otras cien por su alma. En aquel acto jurídico nombró por herederos a sus dos hijos legítimos: Juan Manuel y Francisco del Villar, para que los lleven, gocen y hereden con la vendicion de Dios y mia, encargándoles me encomienden a su Divina Magestad. Para cuidar su prestigio social o tal vez para aliviar el peso de sus pecados deja escrito que una vez que se certifique su fallecimiento se repartan seis fanegas de trigo en pan cocido, eso sí, se vuelve a repetir la frase, para que me encomienden a Dios.

Pero lo más noticiable para nosotros fue el testamento otorgado previamente ante el escribano don Juan Ruiz de Montenegro ${ }^{12}$. Además de las obligaciones espirituales y mandas propias que acompañan a este tipo de documento, es el tiempo de conocer la fortuna personal que logró reunir nuestro aparejador. De entrada él mismo calcula que a sus dos descendientes les deja en metálico y en propiedades una cantidad que ronda

11. ADCR. Libro de Difuntos $n^{\circ} 7,1802-1815$, f. 128. El día exacto de su fallecimiento fue el día 3 de septiembre de 1806; el entierro se llevó a cabo al día siguiente.

12. AHPCR. Protocolos Notariales. Legajo 04890, fs. 323 y ss. Está fechado el 27 de agosto de 1806, justo una semana antes de su expiración. 


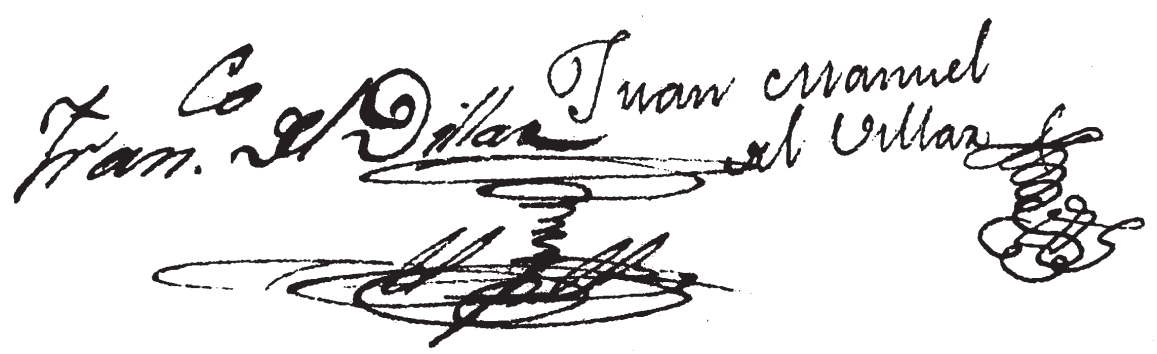

AHPCR. Protocolos Notariales. Legajo 04890, f.348. Detalle de las firmas de ambos herederos.

los 50.000 rs. a cada uno. Asimismo, hace explícita su voluntad de que el molino de La Virgen pase a ser propiedad de su hijo Juan, al que deja 2.000 rs. para las reparaciones que se necesitan efectuar para que siga productivo.

Tras ello, aclara que tiene algunas deudas, dando relación tanto de las personas a las que se les debe abonar, como de aquéllas a las que se les tiene que cobrar. De forma sucinta los cargos que tenía pendientes serían los siguientes:

al hospital de la Caridad, cuatro mil rs.; a Francisco Conejo y D. Ramon de Torres, partícipes en la ciudad de Toledo tres mil; al referido D. Juan mi hijo mil quatrozientos noventa y dos; a Alfonso Cabrera doszientos y ochenta, para los que le tengo entregadas ocho y media fanegas de zebada.

Luego, recuerda los retrasos con el guarda que cuida de su ganado; con el propio escribano que redacta el documento; con el administrador de rentas del ayuntamiento y antiguo alguacil mayor, don José de Lara, y con las hermanas Brígida y Josefa Gilo, a las que manda hacerles llegar, en forma de legado o como mejor corresponda, 100 rs. de vellón a cada una.

En ese mismo mes de septiembre, una vez que enterraron a su padre, los dos hijos tuvieron que proceder a la partición, división y recíproca adjudicación de los bienes y efectos que pertenecieron al finado, don Antonio del Villar, al que el escribano menciona como subdirector de Arquitectura de estos Reales Establecimientos ${ }^{13}$. La valoración y reparto de los enseres que había en los distintos habitáculos de la casa es pormenorizada. De tal forma que, además de las pertenencias propias de cualquier hogar de cierta fortuna, como sillas, espejos, láminas, utensilios de cocina (sartenes, frascos, loza o cántaros de cobre incluidos), escritorios, algunas piezas de plata (cubertería, relicarios, bandejas o salvillas), tinajas de barro, jamones o mantecas de la despensa, etc., nos interesa destacar, por un lado, trece mapas de diversos tamaños, de los que desgraciadamente no sabemos nada, pero que por su oficio estarían vinculados a las minas y/o encargos efectuados.

13. AHPCR. Protocolos Notariales. Legajo 04890, fs. 343-348. 
Fuera del hogar paterno, llama la atención la variedad de bienes que poseía nuestro aparejador. De forma abreviada se dividieron entre Juan Manuel y Francisco:

- La cosecha anual de grano almacenada, donde tras explicitar lo que faltaba por débitos y lo vendido para satisfacer algunos créditos, se repartieron los dos hermanos 48 fanegas y media de trigo, 86 de cebada y 3 de centeno.

- El ganado que se cuidaba en la vacada del concejo: 22 vacas grandes y pequeñas; 4 bueyes de labor; 2 mulas de labor (una mejor que la otra, por lo que a uno de ellos se le compensó asignándole un caballo); 2 borricos y 2 carros.

- Entre las fincas: cuatro suertes en la dehesa de Castilseras, otra que compró en vida su padre, más dos terrenos en ese mismo lugar.

- De la piara de 37 cerdos, 5 se adjudicaron cada uno de ellos para la matanza de ese año, y los restantes los dejaron en común para pagar a los posibles acreedores. Ese mismo criterio siguieron con dos yeguas, un carro y una berlina de cuatro ruedas.

Pero sin lugar a dudas lo más significativo y valioso fueron los bienes raíces: el molino de Peña Tejada, con el rodeo inmediato; el molino Blanco y otro contiguo a este; los cercos, olivar, huerta y terreno que llaman de La Pila, camino de Almadenejos; una casa comprada a Pedro Mariosa; dos censos, uno de 2.100 rs. y otro de 1.000; la casa principal y casilla colindante; el portón, huerto y casa del hortelano; la cerca y huerto del Álamo; otra cerca mencionada como de La Dionisia; dos casas propias y en arrendamiento en aquel instante; además del ya citado molino del Retamizo ${ }^{14}$, que se adjudicó a Juan Manuel, en el cauce del río Gargantiel. En las disposiciones finales del documento se hace un balance de lo adjudicado a cada heredero y las compensaciones y adjudicaciones que cada uno recibió. De hecho los 3.319 rs. que tenían en común sirven para equilibrar los desajustes producidos.

Este conjunto patrimonial nos hace pensar en el importante progreso económico que alcanzó el mocejonero, fruto de su esfuerzo y talento personal, de las relaciones familiares que entabló, de la información privilegiada de que dispuso y de una brillante carrera profesional, como tendremos ocasión de comprobar ahora.

\section{SU CARRERA PROFESIONAL. DE APRECIADOR DE CASAS A SUBDIRECTOR DE ARQUITECTURA}

Intentar compendiar los cuarenta y siete años de servicios prestados en estos cercos por este toledano es una labor ardua, ya que por su perfil profesional tendrá que participar anualmente en varias ocasiones en actos de tasación jurídica o en contratas con las minas. Por ello, nos centraremos en aquellos momentos más relevantes, en los que haya marcado mayor impronta su intervención, dejando una breve relación de los que no tengan tanta trascendencia para el futuro. Para facilitar su estudio los vamos a englobar en dos bloques; por un lado, los referidos al consistorio y, por otro, los estric-

14. AHPCR. Protocolos Notariales. Legajo 04883, f. 22 y ss. En enero de 1790, tras la muerte de su antigua dueña, María Jiménez Cordobés, aparece en una puja muy reñida en la que terminó adjudicándose esta propiedad. 
tamente relacionados con las Reales Minas de Azogue, aunque en el caso de la villa que nos ocupa, resulte difícil a veces distinguirlos. Comenzaremos por los lazos que le unen al Ayuntamiento.

La primera noticia que tenemos de él será como apreciador de casas en los nombramientos que el municipio hace a comienzos del año 1759. Su compañero en aquellas obligaciones será Juan Rodríguez Polito ${ }^{15}$. Desde luego que esta tarea es la de mayor recorrido temporal, puesto que hasta su fallecimiento raro es el año que no ejerce esa función, aunque, obviamente, los compañeros tasadores van a ir cambiando con el transcurso del tiempo. Entre los más repetidos, junto al arriba mencionado Juan R. Polito, estarán Juan Santiso (su fiador y avalista), Juan Perianés, Antonio Lucía, Juan Antonio Perea o Ángel Sierra.

A partir de ese instante serán incontables las ocasiones que aparece su nombre en las actas municipales y en los protocolos notariales. Las circunstancias pueden ser de lo más diversas: arreglos de caminos, compraventa y transacciones que permitan abrir el callejero ante la expansión de viviendas, tasación de inmuebles por la imposición de censos y un largo etcétera. Por ello, citaremos sólo algunas a modo de ejemplo. Así, en el verano de 1774 se le encomienda armar con maderas los graderíos para los festejos taurinos celebrados los primeros días de agosto ${ }^{16}$. En mayo de 1786, al nombrarse administradores de la renta del tabaco a Antonio Sánchez Caravantes, éste y su mujer tienen que aportar como aval de su contrato las casas que poseen, por lo que Antonio del Villar tendrá que evaluarlas y tasarlas ${ }^{17}$. Sólo dos años después, en otoño de 1788, su colega Juan Antonio Perea pide un censo de mil ciento treinta y ocho rs. a la iglesia parroquial sobre los caudales de Nuestra Señora de Gargantiel, por lo que nuestro aparejador debe peritar la vivienda que aquel tenía en la calle san Pablo ${ }^{18}$. Y ya que citamos a Gargantiel, en 1802, a una edad avanzada, aceptó el nombramiento de alcalde de aquella aldea y mayordomo de la Virgen, cargo de carácter honorífico pero de trascendencia local, pues se reservó durante décadas a personalidades destacadas de la sociedad almadenense. Estas breves pinceladas prueban la intensa actividad que mantenía Villar por aquellos años a título particular.

Pero centrémonos en lo que concierne a sus obligaciones con el establecimiento minero. El primer contrato, que aportamos a continuación, se firmó en julio de $1761^{19}$. En aquel momento se obligaba con la Real Hacienda a fabricar y suministrar la teja y el ladrillo que se necesitase hasta el día de san Juan del año siguiente. Se ajustó el

15. Archivo Histórico Municipal de Almadén (a partir de ahora AHMA). Legajo $\mathrm{n}^{\mathrm{o}}$ 34. Quiero destacar la importancia de este archivo y la generosidad con que he sido tratado en él por parte del historiador Luis Miguel Montes.

16. AHN. F.C. Minas Almadén. Legajo 1187.

17. AHPCR. Protocolos Notariales. Legajo 04881. Aquí aparece junto a otro maestro alarife, Ángel Sierra.

18. AHPCR. Protocolos Notariales. Legajo 04882. La fecha exacta de ambos documentos el 4 y el 8 de octubre de 1788.

19. AHN. F.C. Minas Almadén. Legajo no 224 (1). En esta misma documentación se encuentra el contrato de los referidos Juan Segador y Francisco Ávila, ratificados el 5 de septiembre de 1761. 


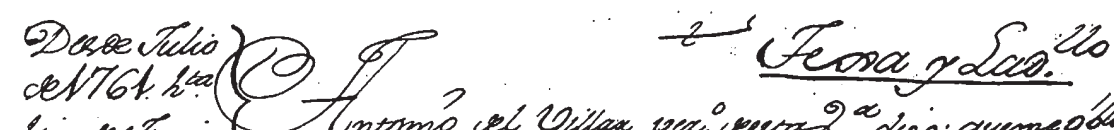

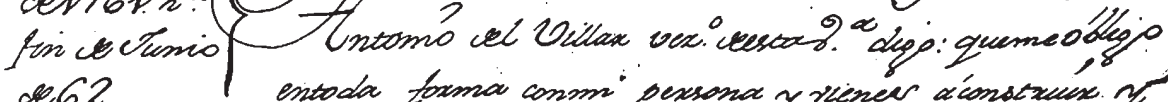
L62. I entoda forma conm pexsena y rieneer x́conscruex.

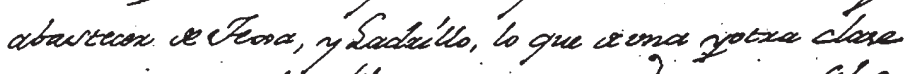

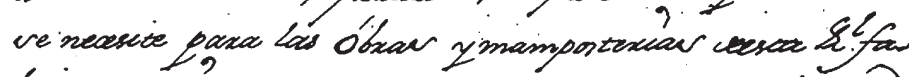
bxicix y Ulinaer pox on anso que cumplixa en fin 0

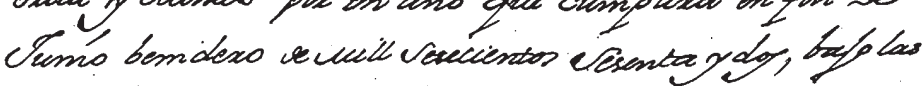
condeciones quicumstanciar ciguicinter.

Gue hade ver cem Cuenta el habilitaxi el hosno llamad o

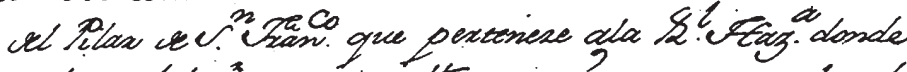
vehade fabriciar yrosiex thas expecies coms tambien lay composizioner que necesitaxe duxante el añ. cescin Oblegacion.

In poxiada Ciento Nadxitlos Comineer vela calidas, que

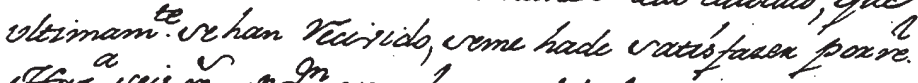

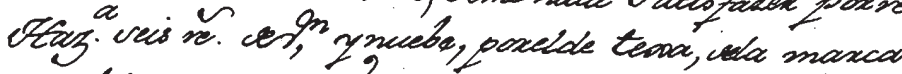

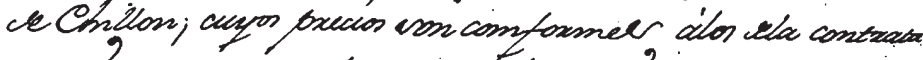
anteriox ausa, qree ha rematado en mon poxno habex paxecids postox meloxante enel timpo cere publicaxion Tes condicion, queenel expreseds honno, nove hade podex as.

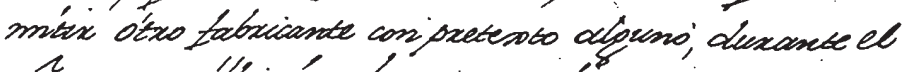

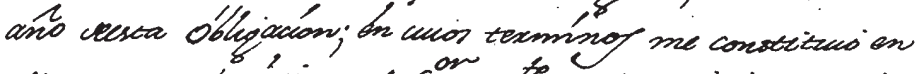

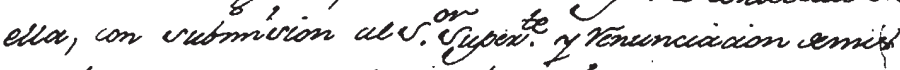

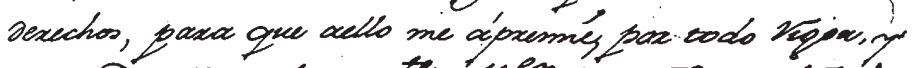

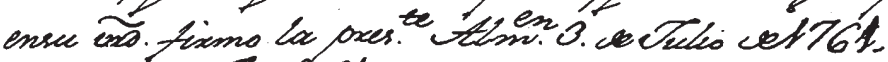

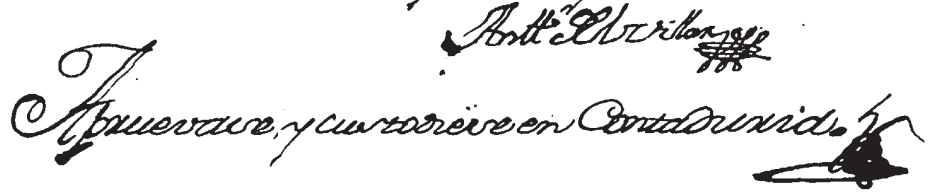

AHN. FC. Minas Almadén. Legajo no 224 (1). Contrato de Teja y ladrillo de Antonio del Villar.

centenar de ladrillos en 6 rs. de vellón y el de teja en nueve; eso sí, cocidos ambos materiales en el horno del pilar de san Francisco (cuyas reparaciones, si los necesitase, corresponderían de su cuenta). Se hace esta precisión, ya que el resto de obra de tejera 
para ese mismo año se adjudicó a Juan Segador y Francisco Ávila, vecinos de Chillón. Estos firmaron unas condiciones económicas más ventajosas por su trabajo (10 rs. por cada centena de tejas y ladrillos cocidos), pero lo que es más relevante, se labrarían en el horno que se ubicaba en el interior del cerco de Buitrones.

Serán reiteradas las ocasiones en que veamos estampada su firma y rúbrica en los documentos mineros. También aquí las situaciones pueden ser de lo más variopintas, pues igual aparece valorando la casa que Rafael González, avecindado en Almadén, pone como garantía por haberse hecho con el servicio de distribución de géneros comestibles del Real Hospital y Taca del Real de Minas de Almadenejos ${ }^{20}$; que cumpliendo idéntica función de peritaje con las fincas de Juan Antonio Martín de Lucía, escribano, que al ser nombrado mayordomo de guarda-almacén de la mina del Castillo tiene que avalar hasta quince mil rs. para asegurar posibles resultas en su nuevo oficio $^{21}$; o bien interviniendo en ventas judiciales de inmuebles a favor de los cercos mineros; o tasando los arreglos de caminos que se dirigían a Almadenejos, donde el asentador que se había comprometido con la Hacienda era su compañero Ángel Sierra.

Pero, a nuestro entender los contratos más relevantes que firmó o supervisó el aparejador toledano de aquellos a los que hemos tenido acceso son los siguientes: la obra de mampostería que permitiría construir una casa y cuarto para colocar en ella la máquina en la mina del Pozo (dentro del torno superficial de san Teodoro), trabajos que se desarrollarían entre 1770 y 1772; las tres casas que se habían de levantar en las minas de las Cuevas en 1775; los arreglos en la torre y capilla mayor de la iglesia parroquial y en la ermita de Jesús Nazareno, como consecuencia de los rayos y centellas caídos en el otoño de 1778; la construcción de todo el perímetro murado del cerco de Buitrones en 1779; la edificación de la casa de la Carnicería, que serviría a la larga también de almacén de grano entre 1779 y 1781; la dirección de las obras de la Academia de Minería, entre 1781 y 1785, y las labores que permitirían reparar y volver a centrar el malacate en las entrañas subterráneas en 1789, que en buena medida complementaban lo realizado veinte años antes.

En cuanto al primer asiento ${ }^{22}$, el de los trabajos para edificar la casa que contendría la máquina de la mina del Pozo, del que mostramos esta hermosa lámina coloreada que ayuda a interpretar con mayor precisión el contenido y envergadura del proyecto, el propio Antonio del Villar nos explica que su ejecución se debería de ajustar con arreglo al plan, perfil y relacion que presente al sr. superintendente..., dando a las murallas de la casa y quarto de la máquina los gruesos, longitud, latitud, dimensiones y solidez que corresponde.

El precio presupuestado para todo ello ascendía a 48.500 rs., que se irían pagando según se fueran certificando los avances de lo ejecutado. Entre las condiciones

20. AHPCR. Protocolos Notariales. Legajo 04881.

21. AHPCR. Protocolos Notariales. Legajo 04815.

22. AHN. F.C. Minas Almadén. Legajo 224 (2). Carpetilla titulada: Contrata de Antonio del Villar para la construccion de la maquina del torno de S. Theodoro de la mina del Pozo. Dentro: la escriptura de fianza y el cargo de los mrs. que recibe por cuenta del precio en que se combino. 


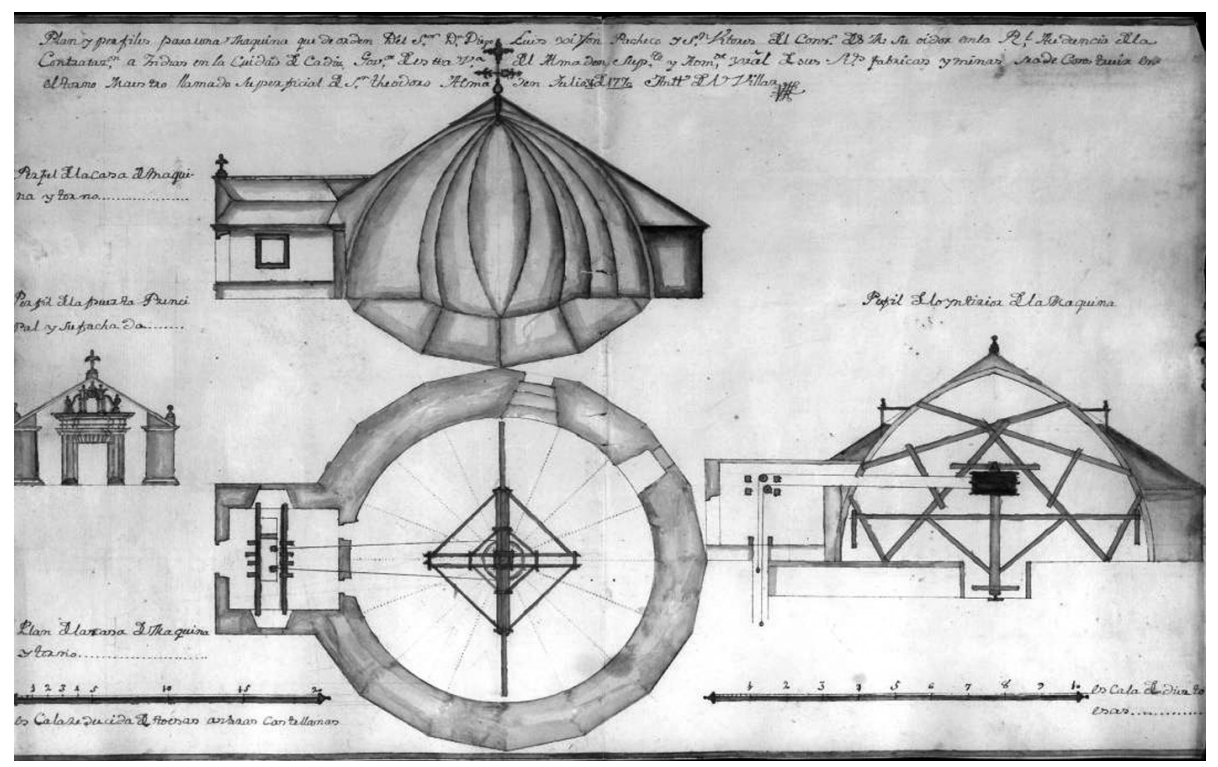

AHN. F.C. Minas de Almadén. Legajo no 224 (2). Plan y perfiles para una maquina que de orden del sr. D. Diego Luis Xijon Pacheco y SanVitores del consejo de S. M., su oidor en la Real Audiencia de la Contratacion de Indias en la ciudad de Cadiz, Governador de esta villa del Almaden, Superintendente y Administrador Xeneral de sus R. Fabricas y Minas, se a de construir en el torno maestro llamado superficial de S. Theodoro. Almaden y en julio 31 de 1770. Firmado y rubricado: Antonio del Villar.

pactadas: a) que las explanaciones y desmontes para la cimentación corrían a cargo del contratista; b) que todos los útiles, cuerdas y herramientas que se necesitasen se los entregaría la Hacienda, pero al final de la obra se devolverían en buen estado o se abonarían los no entregados, inservibles o extraviados; c) que la empresa le pondría a pie de obra los materiales precisos (arena, cal, ladrillo, piedras, maderas y herrajes); d) y que como fianza se ofrecerán bienes raíces por valor de 18.000 rs., que el matrimonio aporta de forma conjunta. Por cierto, que el verificador que se nombra para supervisar los avances y estado de lo construido será su colega Juan Rodríguez Polito.

La segunda intervención va ligada al descubrimiento de la mina de Las Cuevas en 1774. Tras ese hallazgo la Hacienda se verá obligada a edificar las instalaciones indispensables para la explotación y gestión de los recursos que allí se tenían que laborear. Por tanto, al año siguiente el superintendente Soler acepta el presupuesto que le presenta Antonio del Villar en el otoño de 1775. El montante final es más modesto que los restantes, pues se queda en 5.890 rs., explicitando que están incluidos en ese presupuesto las mezclas, el agua y el cernir la tierra, pero que el resto de materiales y utensilios los pondrá la administración a pie de obra.

Como se puede apreciar en el plano aportado, la zona más amplia corresponde a corrales. Las tres casas que ocupan la fachada principal corresponden, de izquierda a 


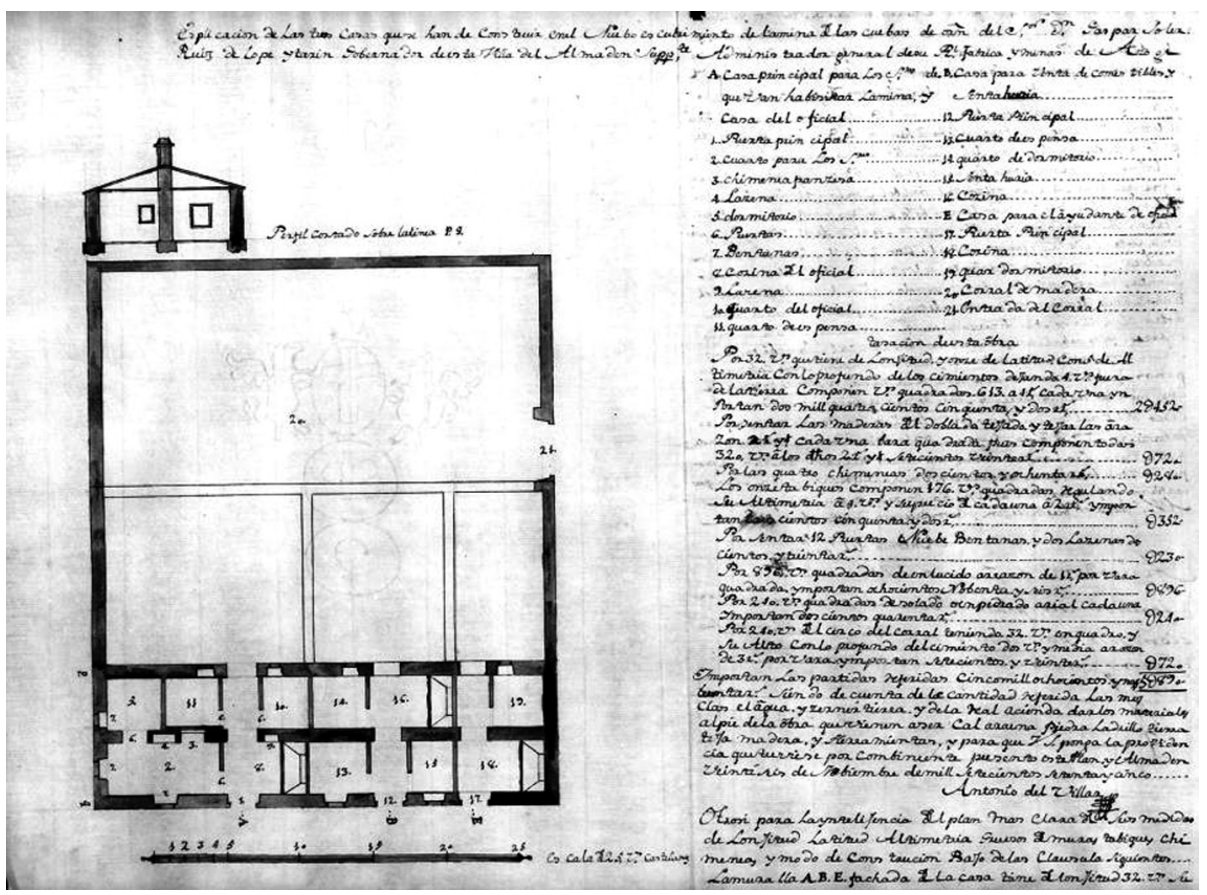

AHN. F.C. Minas Almadén. Legajo 224 (2). Detalle de la parcela a construir contando como referencia una escala de 25 varas castellanas.

derecha, la primera al oficial allí destinado con todas sus dependencias (cuartos privados, cocina, alacenas y despensas); la segunda, a la venta de comestibles y sentaduría; mientras que la otra que hace esquina la ocuparía el ayudante del oficial. Este plano se acompaña del perfil y una pequeña memoria de calidades, donde se especifican el número de tabiques que se han de levantar, las cuatro chimeneas que se obrarán o los tipos de enlucidos, solados o empedrados que se emplearán.

En lo tocante al tercer trabajo, las reparaciones que tuvo que llevar a cabo nuestro aparejador en la fábrica de la torre y la Capilla Mayor de la iglesia parroquial como consecuencia de los daños causados por «la centella o centellas» en septiembre de $1778^{23}$, se hicieron a expensas de la administración minera, quien luego se entendería económicamente con la iglesia para cubrir los gastos. En breve, aprovechando la coyuntura, presentó otro informe sobre los arreglos que necesitaba la ermita de Jesús Nazareno (techo del crucero, lateral norte, techo del cuarto del santero, tejas rotas en la zona de la Sacristía) cuya tasación de materiales y mano de obra ascendió a 2.550

23. AHN. F.C. Minas Almadén. Legajo 60 (1). 


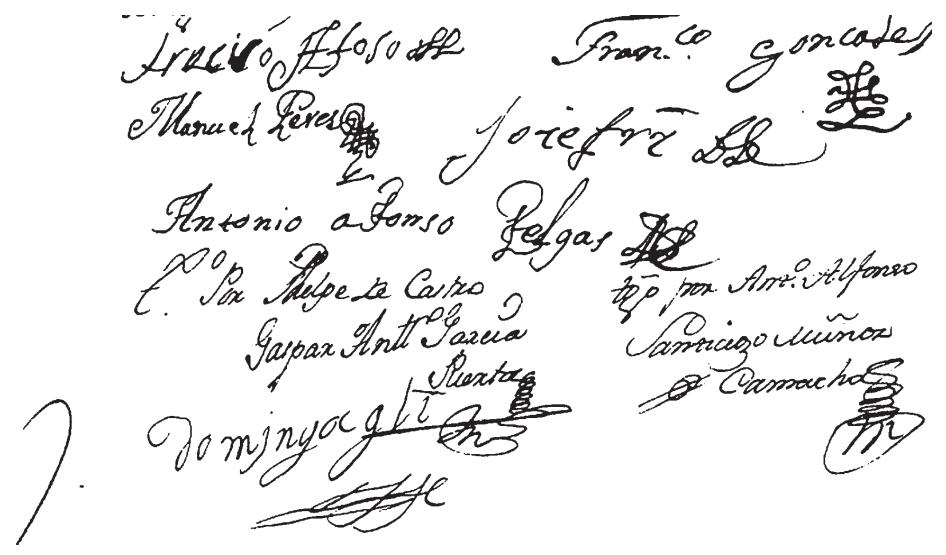

AHN. F.C. Minas Almadén. Legajo 224 (2). Detalle de las firmas de los albañiles asentistas portugueses.

rs. La forma de pago, admitida por el superintendente, volvió a ser idéntica, primero anticipaban los gastos las arcas mineras y más tarde los abonaría el párroco.

Respecto a la obra del cerco de Buitrones ${ }^{24}$, aunque a él se le menciona como participante en las plicas para hacerse con esta contrata, tras sucesivas mejoras se la terminan adjudicando a maestros alarifes portugueses. Bien es verdad que será el toledano quien ejerciendo como aparejador irá visando los progresos en los muros. Los ochos albañiles lusitanos, cuyas firmas y rúbricas adjuntamos en la imagen que se acompaña, acuerdan los siguientes puntos:

- Que el basamento y el remate del muro deberá medir tres cuartos de vara, alcanzando la altura total de cinco varas y media, al margen de lo que ocupe la albardilla (que estará bien sentada de cal y arena).

- Que la línea de levante a poniente formará un ángulo, cuyos lados recorrerán 25 varas desde el torno de san Sebastián hacia el Oeste y el otro 40 al Este. Que los lados que se levantarán de Norte a Sur tendrán como punto de referencia la puerta principal, guardando treinta metros a izquierda y derecha de ésta.

- Que todos los materiales - cal (pagada por cuenta de esta fábrica), arena, ladrillo, piedra, agua y madera para andamios - habrían de sufragarlos la Hacienda y arrimados a pie de obra.

- Que al igual que en el contrato anterior, las herramientas y útiles que se necesiten se recibirán para su uso por la administración, comprometiéndose a devolverlos en buen uso o abonar su valor.

- Que al ser irregular el terreno en que se levanta el muro, se diferencia el valor de cada vara cúbica de lienzo de pared subida, según la desigual orografía. Aunque por término medio se calculan tres rs. por cada una de ellas construidas.

24. AHN. F.C. Minas Almadén. Legajo 224 (2). Carpetilla: Año de 1779. Obra del cerco de Buitrones. 
- Que toda la obra se habrá de entregar nueve meses después de la firma, por tanto en diciembre de 1779. No obstante introduce una salvaguarda, que en caso de que por falta de materiales no pudieramos continuar la obra, se nos devera prorrogar el tiempo por el que nos obligamos a su conclusión.

Otra edificación relevante será la casa de la Carnicería Pública, erigida entre 1779 y 1781. También aquí dio la planta y el alzado nuestro ilustre maestro mayor de obras. Las transformaciones han sido tan radicales que nada de lo antiguo se mantiene hoy en pie. De hecho, a pesar de que actualmente se conserva en el mismo emplazamiento de entonces, su función es diametralmente opuesta, ya que allí se custodia (en unas condiciones nada acordes con los tiempos actuales) el valioso Archivo Municipal.

\section{LA ACADEMIA DE MINERÍA (1781-1785)}

Sin lugar a dudas la obra señera y de mayor renombre del maestro alarife, por su valor institucional, fue la planificación y ejecución de la Academia de Minería, en los primeros años de la década de los ochenta. Pero antes de llegar a ese instante conviene recordar algunos detalles previos que harán comprensible su gestación y primeros directores. Así, en los años cincuenta, para impulsar y sistematizar las labores mineras, se decidió por la Corona la llegada de técnicos y mineros alemanes. Si bien esta resolución ya estaba tomada, pues la primera gran remesa fue encargada al naturalista irlandés Bowles en 1754, la misma se vio impulsada tras el gran incendio de 1755. La presencia de estos hombres y sus familias, mayoritariamente sajones y luteranos, tendrá para el futuro social y religioso de la villa una enorme repercusión, aunque ahora lo que nos ocupa son los aspectos constructivos y organizativos de la institución minera.

A través de la documentación conservada tenemos noticia de los cargos de responsabilidad más importantes que llegaron a estas cárcavas mercuriales. De algunos de ellos se puede seguir su pista, tal es el caso del primer director facultativo, Henning Carlos Köehler, a quien, mediante escritura de obligación otorgada ante don Francisco Javier Villegas en Almadén en enero de $1756^{25}$, le cupo el honor de iniciar la serie de rectores foráneos. Él mismo justifica su presencia de esta forma, que de orden de $S$. M. fue solicitado y conducido desde Strasburg a esta villa para establecer la dirección y labores de las Reales Minas de Azogue por don Guillermo Bowles, comisionado que dijo ser de la Corte de España para este efecto. En los doce capítulos que firmaron, además de las obligaciones propias (levantar planos de los cerros de Almadén y Almadenejos, la dirección de los filones, el sistema de enmaderar «al modo alemán» y un largo etcétera) quedaba meridianamente claro, que a pesar de su cargo estaría supeditado, dentro y fuera de la mina a las directrices que la superintendencia le indicase.

25. AHPCR. Protocolos Notariales. Legajo 04780. En este convenio entre el Estado y el maestro alemán se concretó en enero de 1756, pero antes se había redactado un "precontrato» en Almadenejos (diciembre de 1755) y elevado una propuesta el superintendente Villegas, que al ser aceptada por don Julián Arriaga, secretario del despacho de Indias y Marina, se ratificó y capituló en aquel acto jurídico. 
Su gestión, obviamente marcada por la catástrofe incendiaria, fue corta, ya que falleció en el verano de $1757^{26}$.

En breve será reemplazado por Enrique Cristóbal Stor, auxiliado por Juan Estembach, al que se le encomendó la tarea de enseñar a los jóvenes matemáticos que se le remitieran de estos reinos y los de América, la geometría subterránea y la mineralogía $a^{27}$. Su trayectoria no fue nada sosegada, pues se enzarzó en continuas disputas con otro maestro sajón, Andrés Gaspar Honing ${ }^{28}$, con quien mantuvo criterios diferentes en la explotación y enmaderación de las galerías. En todo caso Stor tuvo la satisfacción de vivir a la concesión de la Academia de Minas $^{29}$ en el mes de junio de 1777, ya bajo el reinado de Carlos III. Jubilado contra su voluntad, por Real Orden de 21 de junio de 1784, no vio acabadas las obras del edificio académico, ya que le sustituyó Juan Martín Hoppensack, a quien se le obligó a permanecer en el cargo durante ocho años, en los que enseñaría la teoría y práctica subterránea a los jóvenes estudiantes en la Escuela de Almadén.

En junio de 1785, recibe Martín Hoppensack un encargo muy especial desde la Secretaría de Indias, dirigida entonces por don José de Gálvez ${ }^{30}$. La cita textual es la siguiente: conviene al servicio del Rey que sin perdida de tiempo remita v.m. a mis manos plano de los hornos de fundición de azogue que hay en esa villa, como los que se llevaron a Nueva España los prácticos destinados al descubrimiento de minas de aquel ingrediente ${ }^{31}$. Además exige que con sumo detalle y pormenor se saquen tres

26. ADCR. Libro de Defunciones $n^{\circ} 4$ de Almadén, f. 17. Su partida de defunción está anotada el 10 de julio de 1757, enterrándose (excepcionalmente) su cuerpo en la ermita de San Juan, tras abjurar de la secta de Lutero y ser bautizado previamente.

27. Datos recogidos por E. MAFFEI, en la Revista Minera, científica, industrial y mercantil, de la que era director. Año de 1877.

28. Matilla Tascón, A.: Historia de las Minas de Almadén. Vol. II: Desde 1646 a 1799. Coeditado por Minas de Almadén y Arrayanes, S. A. y el Instituto de Estudios Fiscales, Madrid, 1987. Existe una edición facsímil patrocinada por la Fundación Almadén-Francisco Javier de Villegas, del año 2005. Sobre las desavenencias y enredos de estos maestros alemanes ver p. 258 y ss.

29. En la segunda mitad del s. XVIII se crearon en toda España, con respaldo regio, diversas Sociedades Económicas del País. (Sobre este particular ver: SARRAILH. J.: La España Ilustrada de la segunda mitad del siglo XVIII. F.C.E., México, 1992 y AnEs Álvarez DE CASTRILlón, G.: «Coyuntura Económica e Ilustración: las Sociedades Económicas de Amigos del País». Economía e Ilustración en la España del siglo XVIII. Barcelona, Ed. Ariel, 1972). Eran lugares de encuentro, debate y análisis, por parte de una minoría culta, donde se intentaba actualizar científica, técnica y económicamente a la nación. Allí se apostó por enviar a jóvenes a formarse en Europa para relanzar la minería. El punto de referencia fue siempre la Academia de Freiberg, primera Academia europea (1766) y paradigmática institución. Bajo su influencia surgieron otras en Francia, Rusia... y en España, la de Almadén.

30. El malagueño don José Bernardo de Gálvez y Gallardo (1720-1787) fue uno de los principales impulsores de las reformas borbónicas. Potenció las Sociedades Económicas de Amigos del País, ejerció como ministro de Indias desde 1776 y fundó el Archivo de Indias. Recibió de Carlos III el título de Marqués de Sonora.

31. AHN. F.C. Minas de Almadén. Legajo 200 (1). Este documento salió de Aranjuez el 9 de junio de 1785 y el 25 de junio se dio aviso al director Juan Martin Opensak. 
copias de esos hornos con la explicación convenientemente clara y detallada, para que qualquiera alarife pueda construirlos sin la menor variación o diferencia. De tal encargo ahora nos hemos beneficiado, ya que se conservan los dibujos originales custodiados, precisamente, en el archivo sevillano.

Durante los años de su gestión hay que destacar que se adoptó en los pozos un nuevo sistema de laboreo, que ya había sido insinuado por Bowles, de bancos y testeros de unos dos metros de altura. Sujetando las presiones de los hastiales por medio de grandes vigas de madera (estemples), sobre los que se colocaba una encamación. Con este modelo, más algunas reformas y el descubrimiento de la mina Concepción de Almadenejos, se incrementó notablemente la producción, al menos hasta que en septiembre de 1792 cesara por conclusión de su contrato ${ }^{32}$. A él le sucederían para concluir la centuria: Juan Federico Mayer (1792-1796), don Manuel Ángulo (1796-1799) y don Manuel Pérez de Estala (1799-1802).

En cuanto a los detalles meramente arquitectónicos, el edificio se empezó a cimentar en 1782 y tres años después ya estaba ocupado. El proyecto corrió a cargo de Antonio del Villar, participando con sus opiniones el director Stor. Éste último, según R. Sumozas ${ }^{33}$, concibió la fachada de la calle principal en ladrillo, posiblemente influenciado por el aspecto que presentaba el Real Hospital de Mineros; pero Villar quiso emular la piedra granítica imitando sillares almohadillados con el fin de dar mayor empaque a la construcción. Era un modo de querer ennoblecer el aspecto exterior usando materiales pobres, pues a fin de cuentas está realizado con argamasa. La entrada principal sirve de eje simétrico a todo el conjunto, quedando el acceso remarcado por un balcón sobre el dintel de dicha puerta. Éste a su vez se remata, sobresaliendo de la línea de imposta del tejado con otro pequeño balconcillo resaltado por un escudo encuadrado por volutas, hoy muy deteriorado, en el que se intuye las columnas de Hércules y en sus cuarteles los símbolos de Castilla y León. Es con diferencia el empleo, aquí sí, de piedra berroqueña, con pilastras y semicolumnas graníticas, lo que otorga mayor interés a esta portada de estética muy neoclásica.

Hacia la calle Mayor de San Juan sólo se alzan dos alturas: la planta baja con ventanales arquitrabados y fuerte rejería, y el primer piso con balcones semicurvos. En la parte trasera, sin embargo, se aprecia el enorme desnivel que hay con respecto al patio y a la otra calle de acceso, hoy inutilizado. Las imágenes mostradas nos dan pie para explicar cómo sería su distribución interna. Se trataría de un edificio repartido en

32. ZARraluQUi MartíneZ, J.: Los Almadenes de azogue (Minas de cinabrio). La Historia frente a la tradición. Librería Internacional de Romo, Madrid, 1934, p. 189, precisa que en 18 de septiembre de 1792 cesa Hoppensack por haber terminado el tiempo de su contrato, con un retiro de 10.000 reales anuales y una indemnización de 6.000 por una sola vez para regresar a su país. Lo cual parece que no sucedió pues en breve lo encontramos explotando por su cuenta la mina de plata de Guadalcanal.

33. Nos referimos a la obra de SumOzas GARcíA-PARDO, R.: Arquitectura Industrial en Almadén: antecedentes, génesis y repercusión del modelo en la minería americana. Ediciones de la Universidad de Castilla-La Mancha y el Secretariado de Publicaciones de la Universidad de Sevilla, Sevilla/Cuenca, 2007. 


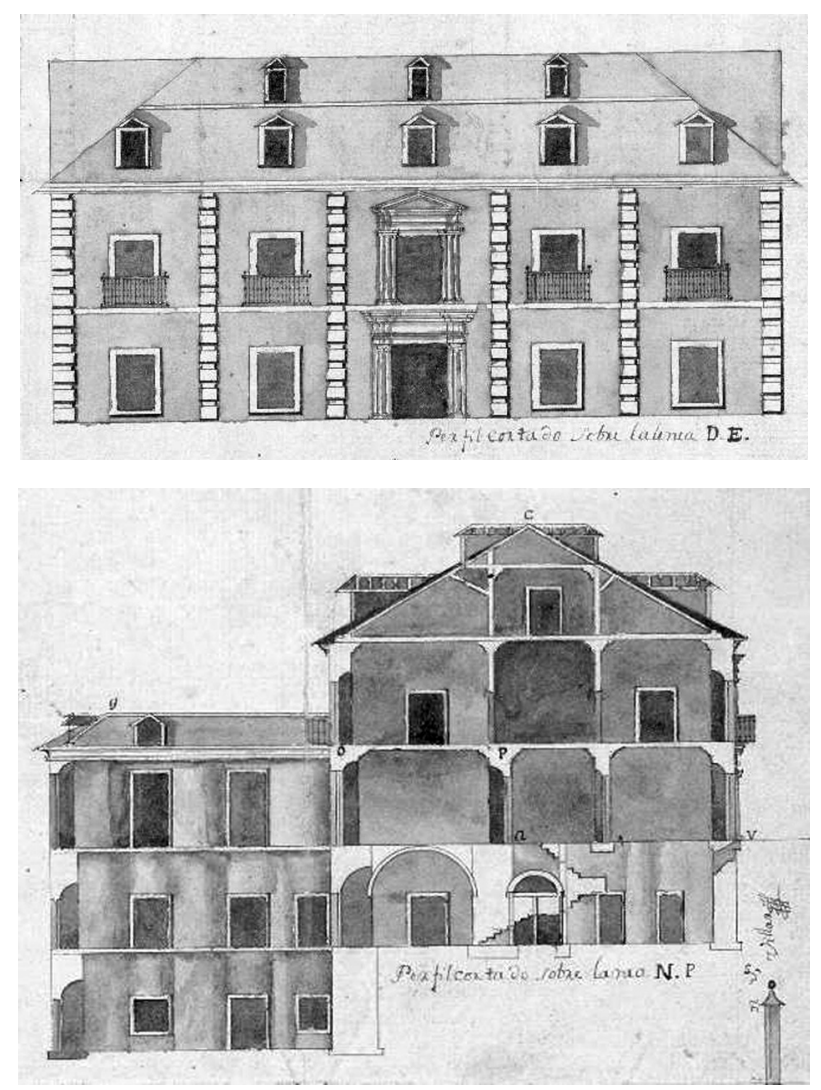

AHN.FC. Minas de Almadén. Legajo 1718. Plano y perfil de las casas para el Director de las minas de azogue de Almadén. Detalle de la fachada principal y de un corte transversal del edificio. Almadén 1782

varias plantas: a) el cuarto principal, que estaría a la altura de la citada calle Mayor, se compondría de antesala, estancia de la chimenea, cocinas con su comedor, despensa para los comestibles, gabinete del director y sala principal, además de la escalera que permite el acceso a las zonas superiores y el sótano; b) el segundo piso, lo configuraría la habitación particular del profesor matemático, zaguán, cuatro salas, un salón principal y las necesarias escaleras de paso; c) la zona inferior, que se subdividiría a su vez en dos franjas: la que da al mediodía, que es el sótano propiamente dicho, con las habitaciones de los alumnos matemáticos y las del director don Enrique Stor, más las cocinas, las dependencias precisas para hacerlas más funcionales y las salidas a la parte septentrional, que permitirían el paso al huerto y al patio trasero, con el gran desnivel. La imagen que vemos de esa zona posterior permite distinguir los aditamentos y añadiduras que ha ido soportando el inmueble a lo largo de su historia, ya que ha servido en las últimas décadas de institución educativa, asilo de ancianos, cuartel militar en la 
guerra civil, taller de costura y guardería municipal. Desde luego, este inmueble hoy reclama una pronta restauración.

Por cierto, que cuando se hallaba inmerso en la construcción de este emblemático edificio se produjo la visita del ilustre ingeniero canario don Agustín de Betancourt y Molina $^{34}$ (1758-1824). Personaje que llegó a estas tierras en 1783, por tanto con veinticinco años, tras completar su formación en Madrid. En la Corte recibió entre otros encargos, a través del conde Floridablanca, el estudio de las minas de Almadén. Fruto de los meses que vivió en la villa minera fueron unas escuetas, pero interesantísimas Memorias.

La primera de ellas versaba sobre el problema de las aguas. A lo largo de tres capítulos da cuenta de los parajes donde se acumulaba el agua, el número de bombas y zacas con que se extraía, las personas y jornales que ello requería o el método seguido en el desagüe. Como apéndices incluye un cuadrante con el estado de las aguas en la mina del Almadén y dos estampas autógrafas muy instructivas.

La segunda Memoria, que es la que ahora nos interesa resaltar, desglosada en seis artículos o epígrafes, se centra en el estudio de la maquinaria empleada en los trabajos de extracción del mineral. En la introducción, explica una serie de voces usuales en esta especialidad. En el primer artículo detalla cómo es el acarreo del mineral en el interior de las galerías; en el segundo, cómo se sube el mineral por tornos; en el tercero, cómo se extrae el mineral fuera de la mina; el cuarto versa sobre la máquina de tambor de Almadenejos; el quinto, sobre la extracción del mineral con carros; y el sexto sobre el modo de bajar la madera en la mina. De igual modo, termina con dos ilustraciones firmadas por el propio Agustín de Betancourt.

La tercera Memoria, centrada en las operaciones que se ejecutaban en el cerco de Buitrones, mantiene el carácter didáctico de las anteriores con un vocabulario de términos propios y unas notas explicativas de las tres estampas y dos dibujos con que la acompaña. A lo largo de cinco capítulos se incide en la invención y construcción de los hornos; en el modo de cargar, cocer y descargar los mismos; en el sistema empleado para sacar el azogue de los caños o aludeles; en las observaciones que hay que efectuar sobre el aire de los hornos; $y$, finalmente, describe el modo de empacar el azogue.

La inspección que Betancourt realizó en Almadén acabó concretándose en varias propuestas de mejora que se llevarían a feliz término, lo que debió de impresionar al Secretario de Estado. Si se desea estudiar con pormenor el recorrido del viaje que le condujo hasta estas tierras calatravas, se conservan unas notas (incompletas) de su

34. En la Biblioteca Nacional (B.N.) se conservan las tres Memorias de BetANCOURT MolinA, A. La primera, Memoria sobre las aguas existentes en las Reales Minas del Almadén, en el mes de julio de 1783 y sobre las maquinas y demás concerniente a su extracción. Ms. 10427; la segunda, Memoria sobre las maquinas que usan en las Minas del Almadén, en que se expresan sus ventajas, y defectos, y algunos medios de remediarlos. Ms. 10428; y la tercera, Memoria sobre todas las operaciones que se hacen dentro del cerco en que están los hornos de fundición del Almadén. Biblioteca Nacional de España. Manuscrito 10429. También se puede consultar una edición facsímil de dichas memorias en: FERNÁNDEZ PÉreZ, J. y GonZÁlez TASCÓN, I.: Memorias de las Reales Minas de Almadén, 1783. Madrid, Tabapress, 1990. 


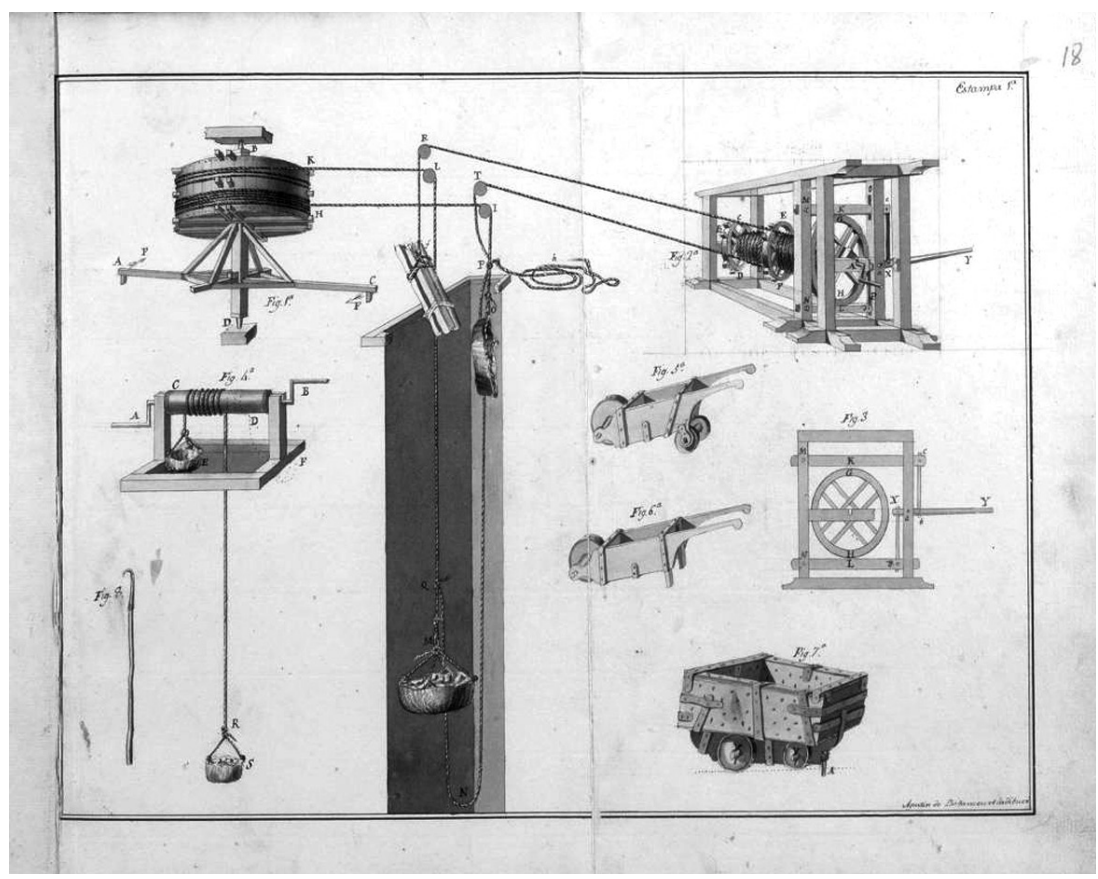

B.N. Ms. 10428. Agustín de Betancourt.-Memoria $2^{a}$, estampa $1^{a}$.

paso, entre otras poblaciones, por Aranjuez, Toledo o Ciudad Real, hasta llegar a su destino ${ }^{35}$.

Si hemos mostrado un mayor interés por esta segunda monografía es por la similitud que guarda el dibujo que el ingeniero canario trazó de la máquina de tambor que se había instalado en la mina de la Concepción de Almadenejos, aldea dependiente en aquel momento de Almadén, con los trabajos análogos que ya había practicado nuestro maestro de obras en 1770 y que en breve tendría que reemprender. Las láminas que acompaña el ingeniero tinerfeño, convenientemente numeradas, no se limitan a dar las explicaciones del procedimiento de extracción, sino que además aporta soluciones muy prácticas que puedan optimar el rendimiento de hombres y animales en la introducción y evacuación de pertrechos y minerales.

Retomando los encargos con el establecimiento minero del que terminó siendo subdirector de arquitectura, nos referiremos al último compromiso de envergadura, del que rescatamos esta espléndida lámina, que es en el fondo una vuelta a lo que veinte años antes ya había erigido el propio Antonio del Villar, sólo que ahora, en la primavera

35. Para conocer el itinerario seguido por don Agustín de Betancourt desde Aranjuez, se puede acudir a la página http://betancourt.fundacionorotava.es. Notas de junio de 1783, carta $\mathrm{n}^{\circ} 4$. 


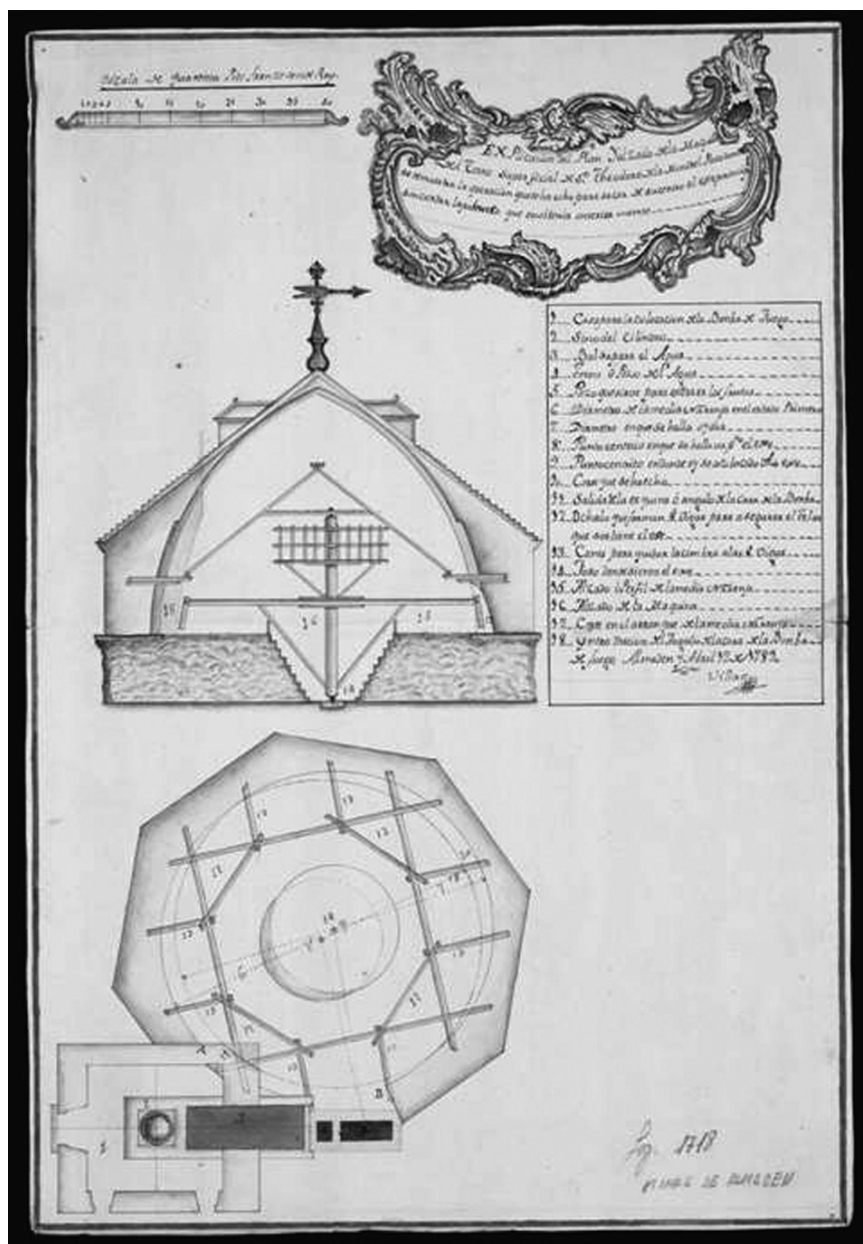

AHNF.C. MINAS ALMADÉN PLANOS. Legajo, 1718. Explicacion del plan y alzado de la maquina del torno superficial de San Theodoro de la mina del Pozo donde se demuestra la operación que se ha echo para sacar de su centro el exe principal, sin cortar la potencia que en si tenia anteriormente. Almadén 17 de abril de 1789. Firmado y rubricado: Villar.

de 1789. En el pliego de condiciones se habla de que se tendrá que centrar el malacate ${ }^{36}$ (suponemos como consecuencia del uso constante a lo largo de esas dos décadas) y, al mismo tiempo, adaptar el espacio existente para recibir la máquina de vapor, aunque

36. El malacate o baritel es un ingenio que consta de un «árbol» vertical provisto de una o varias palancas horizontales en cuyo extremo se enganchan las caballerías, que dan vueltas en torno a dicho árbol. 
aquí será denominada como «bomba de fuego». La leyenda que se incorpora es fundamental para comprender la mecánica y la infraestructura que acarreaba la colocación de este novedoso artefacto: habitáculo para la máquina, balsa de agua (indispensable si se ha de obtener vapor), cilindro y todo el ensamblaje que comporta en superficie y en altura.

Finaliza aquí esta aproximación a un personaje singular, de nacimiento toledano, al que, como a tantos otros, los almadenenses recibieron y avecindaron. En su dilatada trayectoria personal, como hemos tenido ocasión de comprobar, tuvo las alegrías y los sinsabores de muchos de sus contemporáneos: matrimonio afortunado del que nació una amplia prole, constantes disgustos por el fallecimiento de sus seres próximos o por los litigios con su hijo Juan Manuel. En el ámbito profesional, gozó de una gran habilidad en los negocios, ya que lo mismo ejerció de contratista para suministrar teja y ladrillo, que de transportista del azogue hasta las atarazanas sevillanas con un hato de bueyes que adquirió, o de prestamista de censos a quien se los requirió. Si bien es cierto que por los cargos que ostentó, pudo tener acceso a una valiosa información de los inmuebles que tenía que tasar y de los contratos que el establecimiento minero necesitaba cubrir y que ello le hizo prosperar económica y socialmente, puesto que reunió al final de su vida una considerable fortuna personal (fruto de más de una especulación urbanística); también lo es que por su constancia y perspicacia obtuvo el reconocimiento profesional al ser nombrado subdirector de Arquitectura, cuando no era al principio más que un maestro albañil y apreciador de casas.

Estamos convencidos de que en el futuro se podrá ampliar y enriquecer sustancialmente las noticias que vayan apareciendo sobre él. Ahora tenemos la percepción de que estuvo en el lugar oportuno en el momento exacto, es decir, en una villa cuasi industrial (circunstancia excepcional en todo el Campo de Calatrava y en toda La Mancha) en el instante más álgido de su trayectoria histórica, en el Almadén de la segunda mitad del siglo XVIII, cuando el azogue representaba un producto estratégico e indispensable para España. Por si todo ello no fuera poco, descansó para siempre en el cementerio del Real Hospital de mineros, junto a tantos otros protagonistas anónimos, como el médico ilustrado don José Parés y Franqués, con quien convivió cerca de cuarenta años. 